\title{
A new method of 2,6-diaminopimelic acid determination in gut content
}

\author{
D Debroas, N Depardon, G Blanchart
}

\author{
INRA-ENSAIA, Laboratoire de Zootechnie, 2, avenue de la Forêt-de-Haye, \\ 54505 Vandoeuvre-lès-Nancy, France
}

2,6-Diaminopimelic acid (DAPA) is one of the usual markers of bacterial matter in the gut of ruminants. To this end, a new method for determining the DAPA by gas chromatography (GC) in the digestive tract of ruminants is described.

Hydrolysis and clean up procedures. After hydrolysis of $150-200 \mathrm{mg}$ of dry sample (4 $\mathrm{N}$ methanesulfonic acid, $0.2 \%$ tryptamine, $22 \mathrm{~h}, 100^{\circ} \mathrm{C}$ ) (Webster et al, 1990), $1 \mathrm{ml}$ methionine sulfone (1 g/) was added to each sample in order to measure the yield of the extraction reaction and to compensate when necessary. The $\mathrm{pH}$ was adjusted to $7.0-7.5$ by addition of $\mathrm{NaOH}(30 \% \mathrm{w} / \mathrm{N})$. Samples were cleaned up with charcoal-chromosorb mixture (1:1) according to the method described by Czerkawski (1974).

Derivatization. This was carried out according to the method of Husek (1991) in which the proportion of the derivatization reagents were modified to increase the peak area of DAPA. The sample $(40 \mu$ l) was mixed with $10 \mu$ lo the internal standard (L-p-chlorophenylalanine) to a concentration of $1 \mathrm{~g} / \mathrm{l}, 10 \mu \mathrm{l} 0.1 \mathrm{~N} \mathrm{HCl}$ and $40 \mu \mathrm{l}$ ethanol-pyridine mixture (1:4); $20 \mu$ lethyl chloroformiate (ECF) was added. After shaking, $0.1 \mathrm{ml}$ of chloroform-ECF ( $1 \%$ ECF) solution was added.

Analysis. The injector and flame ionization detector temperatures were both $250^{\circ} \mathrm{C}$. Helium was used as the carrier gas $(4 \mathrm{ml} / \mathrm{min})$. The capillary column employed was OV $1701(25 \mathrm{~m} \times 0.32 \mathrm{~mm})$ (Spiral, Dijon, France). The temperature was programmed to increase from $210^{\circ} \mathrm{C}$ to $230^{\circ} \mathrm{C}$ with a

Table I. DAPA determination in the duodenal digesta of different cows (mean and standard deviation).

\begin{tabular}{ccl}
\hline Cow $n^{\circ}$ & $D M\left(M g g^{-1}\right)$ & SD \\
\hline 1 & 0.64 & 0.035 \\
2 & 0.90 & 0.02 \\
3 & 0.61 & 0.02 \\
\hline
\end{tabular}

linear slope of $0.2^{\circ} \mathrm{C} \mathrm{min-1}$ and to reach an end temperature of $262^{\circ} \mathrm{C}$ with a linear slope of $10^{\circ} \mathrm{C}$ min-1.

The DAPA and the 2 internal standards (methionine sulfone and $L-p$-chlorophenylalanine) are correctly separated on the chromatogram (fig 1). With this temperature programming, most of the amino acids were eluted with the solvent. The others (glutamine, lysine, tyrosine and tryptophan) were well separated and did not interfere with the components analysed. The reproducibility of the results (table I) shows that the technique applied here is well adapted to DAPA determination.

This method offers many advantages: the derivatization reagents (ethanol, pyridine, chloroform, ECF) are inexpensive and routinely used.

Czerkawski JW (1974) J Sci Fd Agric 25, 45-55 Husek P (1991) J Chromatogr 552, 289-299

Webster PM, Hoover WH, Millet TK (1990) Anim Feed Sci Technol 30, 11-20

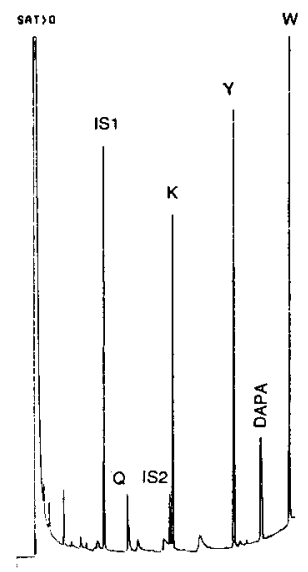

Fig 1. Chromatogram of the mixture of DAPA with various amino acids: $L$-p-chlorophenylalanine (IS1), glutamine (Q), methionine sulfone (IS2), lysine (K), tyrosine $(Y)$ and tryptophan $(W)$. 